\title{
ADSORPTION OF FLUORION FROM AQUEOUS SOLUTION
} ONTO ZR-LOADED CALCIUM SULFATE WHISKER

Li WANG, Yi HuANG, JiNJIN WANG, DAN ZHOU

State Key Laboratory of Geohazard Prevention and Geoenvironment Protection, College of Ecology \& Environment, Chengdu University of Technology, Sichuan 610059, China

High concentration of fluoride wastewater has great harm to human health, so adsorption materials with high fluoride adsorption capacity have always been concerned. In this study, the adsorption effect and mechanism of fluoride ions in water by calcium sulfate whiskers loaded with zirconium under ultrasonic assistance were investigated. Calcium sulfate whisker raw material was mainly composed of calcium sulfate hemihydrate, which has been converted into calcium sulfate dihydrate by hydration after zirconium loading. The point of zero charge $\left(\mathrm{pH}_{\mathrm{pzc}}\right)$ of calcium sulfate whisker with zirconium loaded (Zr-CSW) was 3.6, and the acidic condition was more favorable for fluoride adsorption. The adsorption process of fluoride by $\mathrm{Zr}$-CSW conformed to the Langmuir model and pseudo-second-order dynamic equation, and the maximum adsorption capacity was $258.40 \mathrm{mg} / \mathrm{g}$ at $298 \mathrm{~K}$ and pH 6 7, which is much better than those of many zirconiumcontaining adsorbates. Coexisting anion had little effect on fluoride removal rate, and $\mathrm{Zr}$-CSW had good selectivity to fluoride ion. Alkaline solution had regeneration effect on adsorbent after adsorption, and there might existing strong interaction between zirconium and fluoride ions. The adsorption and removal of fluoride by $\mathrm{Zr}-\mathrm{CSW}$ was mainly achieved by ion exchange between fluoride ions and $\mathrm{OH}^{-}$on the surface of the adsorption material, which can be an adsorption material with great potential for fluoride removal in water. At the same time, it also broadened the application of calcium sulfate whisker in the field of environmental treatment.

Key words: calcium sulfate whiskers; zirconium; fluoride; adsorption; ultrasonic 